\title{
A potential biosorbent from Moringa oleifera pod husk for crystal violet adsorption: Kinetics, isotherms, thermodynamic and desorption studies
}

\author{
Adisak Keereerak, Watchanida Chinpa* \\ Department of Materials Science and Technology, Faculty of Science, Prince of Songkla University, Hat Yai, \\ Songkhla 90110 Thailand
}

*Corresponding author, e-mail: watchanida.c@psu.ac.th

Received 30 Oct 2019

Accepted 25 Apr 2020

\begin{abstract}
Moringa oleifera pod husk (MOPH), an agricultural waste, is presented as a biosorbent for the adsorption of crystal violet (CV) in water. MOPH was characterized using Scanning electron microscopy (SEM), Fourier transform infrared spectroscopy (FT-IR) and Brunauer-Emmett-Teller (BET) analysis. The effects of adsorption parameters on adsorption capacity were optimized. Adsorption of CV by MOPH was rapid in the first $10 \mathrm{~min}$, and equilibrium was approached within $60 \mathrm{~min}$ at all initial CV concentrations. The adsorption kinetics study revealed a good correlation between the pseudo-second order model and the experimental results. The maximum monolayer capacity obtained by Langmuir model was $156.25 \mathrm{mg} / \mathrm{g}$ at $25^{\circ} \mathrm{C}$. The negative values of thermodynamic parameters indicated a spontaneous and exothermic sorption process. The desorption of CV from MOPH was highest in aqueous acetic acid solution, and the re-adsorption study confirmed the reusability of the MOPH biosorbent. Taking into account its abundance, low cost, non-toxicity and its effectiveness and reusability based on the present results, MOPH can be regarded as a promising biosorbent for the CV removal.
\end{abstract}

KEYWORDS: Moringa oleifera pod husk, biosorbent, crystal violet, adsorption

\section{INTRODUCTION}

Crystal violet (CV), a cationic dye, is extensively used in textile dyeing, paper printing, veterinary medicine and biological stain [1]. The effluents released from the utilization of $\mathrm{CV}$ contain poisonous and non-biodegradable dye and compounds, which adversely affect the environment and the quality of human life. Many routes such as biological processes, membrane separation, coagulation, photo-catalytic degradation, photo-oxidation and adsorption can be used to eliminate dye from wastewater [2]. Adsorption is frequently used because it is inexpensive, easy and effective, and the adsorbents could be derived from various materials [3]. In recent years, lignocellulosic materials from agricultural waste have gained interest as alternative adsorbents since they are inexpensive and abundant. The removal of CV using biomass materials has been frequently published. Adsorption capacities higher than $100 \mathrm{mg} / \mathrm{g}$ were not often reported; however, they have been achieved from grapefruit peel [4], wood apple shell (Feronia acidissima) [5], coffee waste [6] and almond shell [7].

Moringa oleifera (MO) is a member of the family
Moringacae. The leaves, pods and seeds of MO are useful for medical and nutritional purposes because they contain a variety of essential phytochemicals [8-10]. Moreover, previous works reported the use of pod, seed and bark of $\mathrm{MO}$ as biosorbents. Bhatti et al [8] presented the removal of Zn(II) using MO pod biomass. MO bark (MOB) was successfully applied to separate $\mathrm{Ni}$ (II) from aqueous solutions [9]. MO seed was used for sorption of yellow dye tartrazine [11]. Tie et al [12] studied the adsorption of congo red using MO seed cake powder, the residual solids from oil extraction.

To our knowledge, a biosorbent from MO pod husk (MOPH), which is the useless part, has not been reported. This work, therefore, presents a study of $\mathrm{MOPH}$ as an alternative adsorbent for the removal of hazardous CV dye. The MOPH was characterized by scanning electron microscopy (SEM), Fourier transform infrared (FT-IR) spectroscopy, Brunauer, Emmett and Teller (BET) analysis and the $\mathrm{pH}$ at point zeta charge $\left(\mathrm{pH}_{\mathrm{pzc}}\right)$. The effects of adsorption parameters on CV adsorption capacity were determined for the following factors: adsorbent dosage, solution $\mathrm{pH}$, adsorption time, ini- 
tial concentration of CV solution and temperature. Adsorption kinetics, isotherms and thermodynamics were investigated. The desorptions of CV from MOPH at different desorption agents and concentrations were also studied, as was the reusability of used MOPH.

\section{MATERIALS AND METHODS}

\section{Materials}

MO pod used to prepare the adsorbent was collected from the local market. CV cationic dye was from Sigma Aldrich. $\mathrm{NaOH}, \mathrm{HCl}$ and $\mathrm{CH}_{3} \mathrm{COOH}$ were from Labscan. All reagents were used without purification.

\section{Adsorbent preparation}

The husks of pod were separated from the fresh pods, followed by water washing. After drying, the MOPH (Fig. 1a) was cut into small pieces and then pretreated with water at $50^{\circ} \mathrm{C}$ until colorless water was obtained. The pieces of MOPH were then dried at $50^{\circ} \mathrm{C}$ for $24 \mathrm{~h}$ (Fig. 1b). Subsequently, they were ground and sieved through a $250 \mu \mathrm{m}$ sieve. The obtained MOPH powder (Fig. 1c) was stored in a desiccator for further study.

\section{Adsorbent characterization}

The morphologies of MOPH were studied using scanning electron microscopy (SEM JSM-5800, JOEL). The chemical groups were analyzed by Fourier transform infrared spectroscopy (FT-IR) (Bruker EQUINOX 55). A laser particle size analyzer (COULTER, LS 230) was carried out to find the particle size of MOPH. The surface area, pore volume and average pore size of MOPH were measured from the Brunauer-Emmett-Teller (BET) method.

The $\mathrm{pH}_{\mathrm{pzc}}$ of MOPH was evaluated using the $\mathrm{pH}$ drift method [13]. MOPH of $0.03 \mathrm{~g}$ was filled to $50 \mathrm{ml}$ of $0.1 \mathrm{M} \mathrm{NaCl}$ solutions at initial $\mathrm{pH}\left(\mathrm{pH}_{\text {initial }}\right)$ values from 2-10. After shaking the mixtures for $24 \mathrm{~h}, \mathrm{pH}$ was measured and noted as the final $\mathrm{pH}$ $\left(\mathrm{pH}_{\text {final }}\right)$. The $\mathrm{pH}_{\mathrm{pzc}}$ was the point where the curve of the plot of $\mathrm{pH}_{\text {final }}$ versus $\mathrm{pH}_{\text {initial }}$ crossed the line where $\mathrm{pH}_{\text {final }}$ and $\mathrm{pH}_{\text {initial }}$ were equal.

\section{Batch adsorption studies}

The adsorption studies were conducted in $120 \mathrm{ml}$ sample bottles to study the effects on CV adsorption of adsorbent dose (0.2-1.8 g/1), $\mathrm{pH}(2-10)$, initial CV concentration (50-250 mg/l), adsorption time $(5-120 \mathrm{~min})$ and temperature $\left(25,35,45^{\circ} \mathrm{C}\right)$. The MOPH was added into sample bottles containing
$50 \mathrm{ml}$ of CV solution. After shaking the mixture at $60 \mathrm{rpm}$, the MOPH was isolated, and the remaining dye in solution was then determined by UVVis spectrophotometry (UV 1601) at a wavelength of $588 \mathrm{~nm}$. Adsorption testing was repeated three times in each case.

The dye removal (\%) and the adsorption capacity $(q, \mathrm{mg} / \mathrm{g})$ were respectively calculated from Eqs. (1) and (2):

$$
\begin{gathered}
\text { Dye removal }(\%)=\frac{C_{0}-C_{t}}{C_{0}} \times 100 \\
q=\frac{C_{0}-C_{t}}{m} V
\end{gathered}
$$

where the amounts of CV in dye solution $(\mathrm{mg} / \mathrm{l})$ at initial time and time $t$ were defined as $C_{0}$ and $C_{t}$, respectively, $V$ is the $\mathrm{CV}$ solution volume (l) and $m$ is the mass of adsorbent $(\mathrm{g})$.

\section{Batch desorption studies}

CV-loaded adsorbent obtained from adsorption experiments was mixed with $50 \mathrm{ml}$ of desorbing agents (0.5, 1.0, 1.5 and $2.0 \mathrm{~mol} / 1$ of $\mathrm{CH}_{3} \mathrm{COOH}, \mathrm{NaOH}$ and $\mathrm{NaCl}$ solutions). After shaking, the remaining $\mathrm{CV}$ in the solution $\left(C_{d}, \mathrm{mg} / \mathrm{l}\right)$ was determined. The percentage of desorption was evaluated from the equation (3):

$$
\text { Desorption }(\%)=\frac{C_{d}}{C_{0}-C_{t}} \times 100
$$

\section{RESULTS AND DISCUSSION}

\section{Adsorbent characterization}

The SEM photographs of MOPH in Fig. 1 show surfaces and cross-sections of MOPH before and after pretreatment with water at $50^{\circ} \mathrm{C}$. Raw MOPH (Fig. 1d) presented a rough surface, but after pretreatment the surface was even rougher (Fig. 1e) and pores are visible in the cross-sectional fractures (Fig. 1h). The SEM results suggest that the pretreatment used in this work partially eliminated lignin, hemicellulose and noncellulosic substances. The SEM micrographs in Fig. 1(f,i) are of MOPH adsorbent in powder form. Using a laser particle size analyzer, the particle size of this powder was found to be $28.35 \pm 21.77 \mu \mathrm{m}$, which corresponds to the range of size and shape presented in Fig. 1f. The rough surface and numerous pores present in pretreated MOPH might facilitate the adsorption of cationic dyes.

In the FTIR spectra of pretreated MOPH (Fig. 2), the transmittance peaks assigned to the 

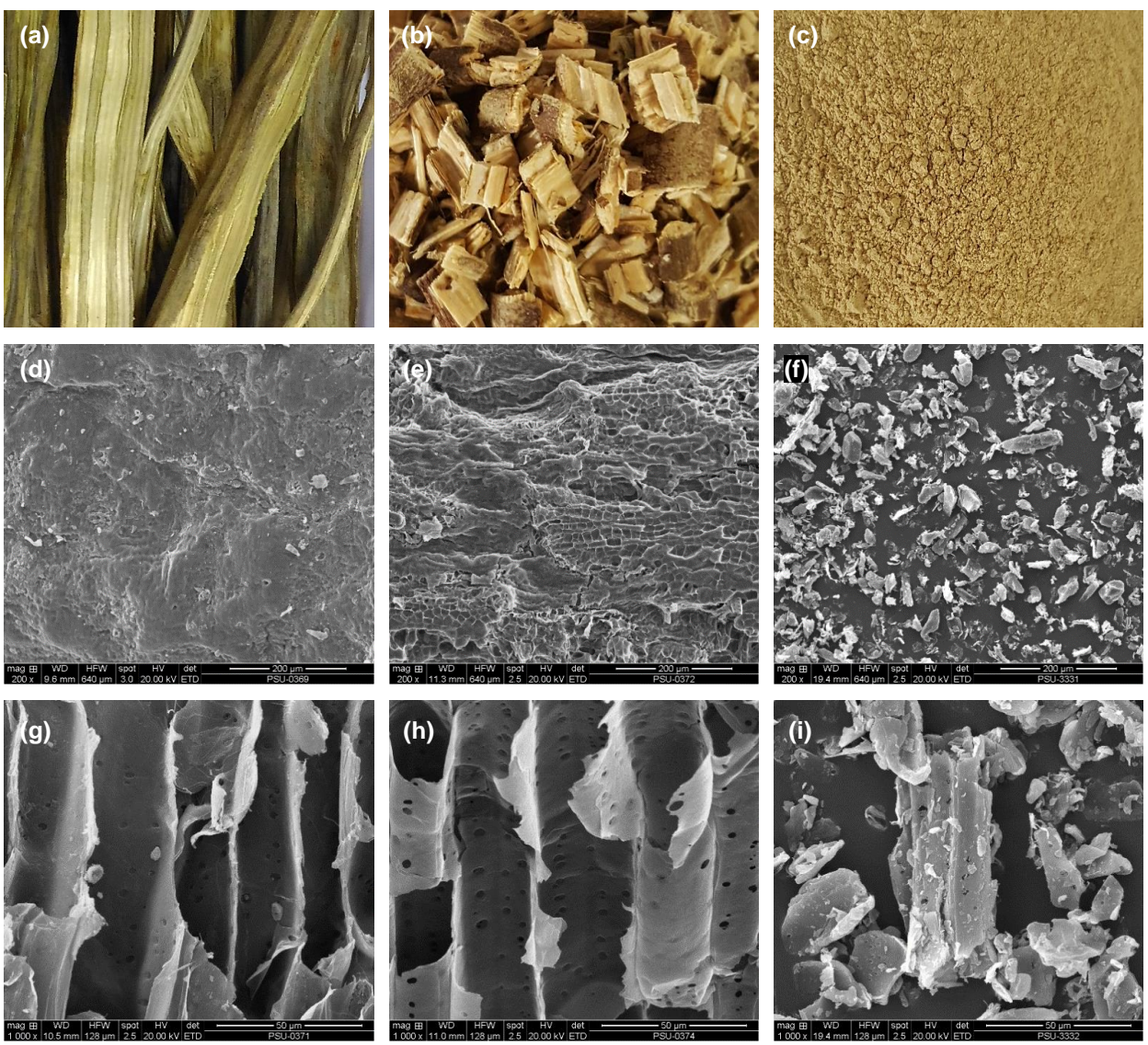

Fig. 1 Photographs and SEM micrographs of surface and cross-section of raw (a,d,g) and pretreated MOPH (b,e,h). Photograph (c) and SEM micrographs at different magnifications (f,i) of pretreated MOPH in powder form.

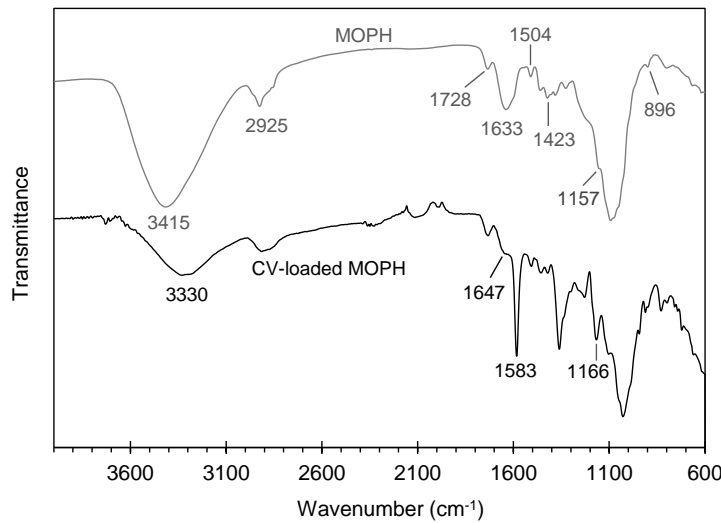

Fig. 2 FTIR spectra of pretreated MOPH powder before and after $\mathrm{CV}$ adsorption.

stretching of $-\mathrm{OH}$ and $\mathrm{C}-\mathrm{H}$ groups of lignocellulose are located at about 3415 and $2925 \mathrm{~cm}^{-1}$, respectively $[14,15]$. The peaks at 1728 and
$1633 \mathrm{~cm}^{-1}$ are attributed to $\mathrm{C}=\mathrm{O}$ stretching of hemicellulose [14-16]. The peaks around 1504 and $1423 \mathrm{~cm}^{-1}$ relate to the $\mathrm{C}=\mathrm{C}$ aromatic ring of lignin $[15,17]$, and the band between 1200 and $1059 \mathrm{~cm}^{-1}$ indicates $\mathrm{C}-\mathrm{O}$ stretching in lignocellulose [17]. The peak at $896 \mathrm{~cm}^{-1}$ indicates the characteristic structure of cellulose [17]. The hydroxyl and carboxylic groups presented in MOPH could bind with cationic dye via electrostatic interaction and hydrogen boding $[6,18]$.

The BET surface area and average diameter of pore of MOPH were $2.097 \mathrm{~m}^{2} / \mathrm{g}$ and $66.268 \AA$, respectively. The surface area of MOPH is in the range previously reported for other agricultural wastes, which was $1.38-11.2 \mathrm{~m}^{2} / \mathrm{g}[18,19]$.

\section{Effect of adsorbent dose}

Fig. 3a presents the effect of MOPH dose on CV adsorption and demonstrates the high level of $\mathrm{CV}$ removal at the higher dosages. The percentage dye 
(a)

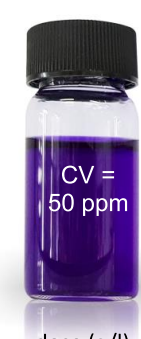

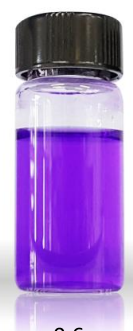
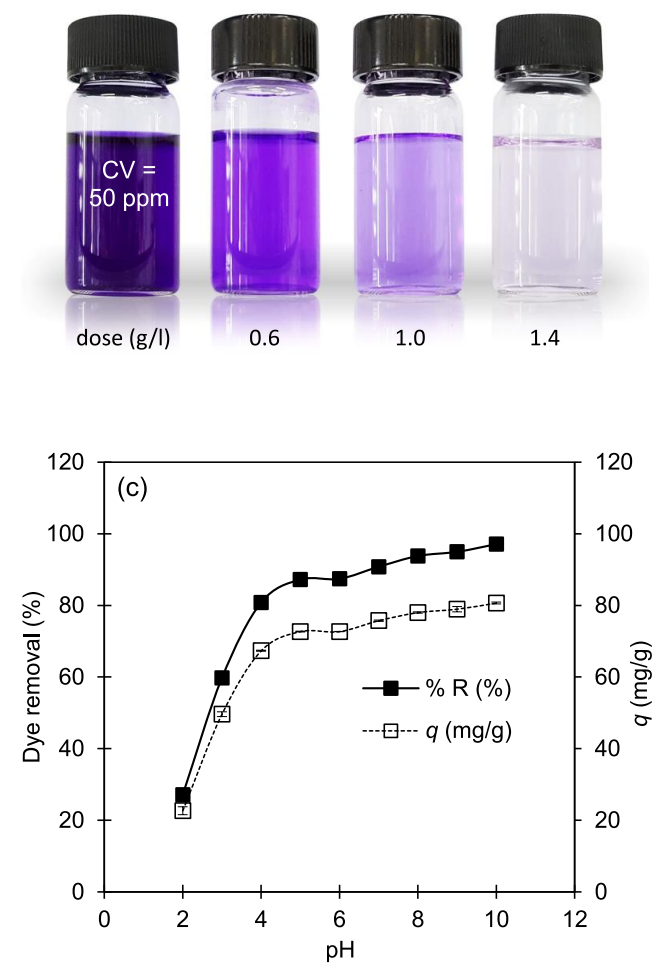
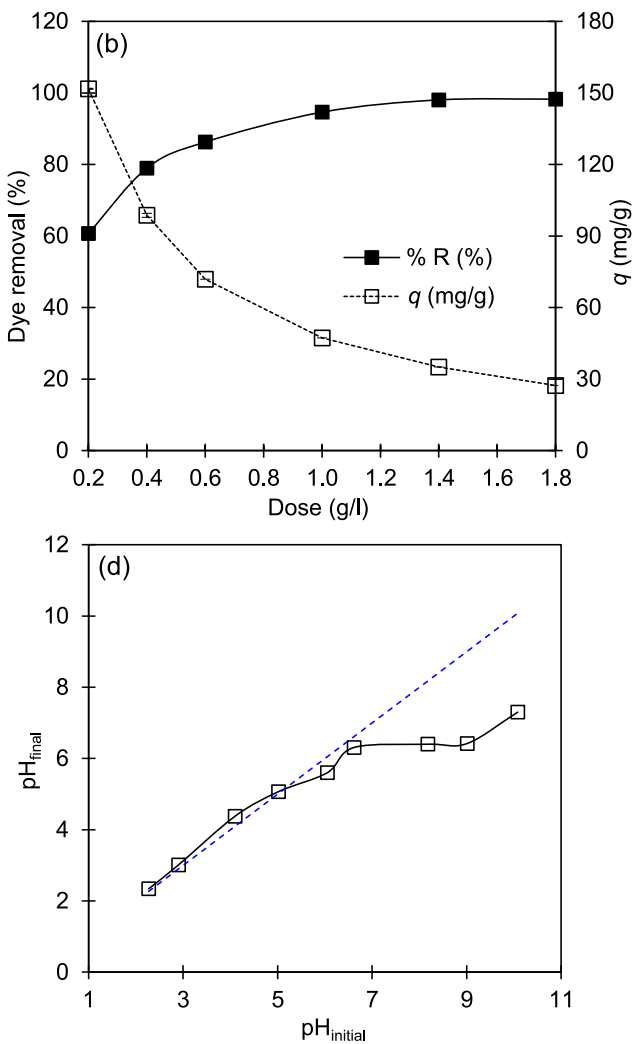

Fig. 3 Effect of adsorbent dose (a,b) and $\mathrm{pH}$ (c) on CV biosorption; and $\mathrm{pH}_{\mathrm{pzc}}$ (d) of MOPH.

removal $(\% R)$ on a MOPH dosage of $0.2 \mathrm{~g} / 1$ was $60 \%$. Dye removal increased to $86.27 \%$ on a dosage of $0.6 \mathrm{~g} / 1$ (Fig. 3b). The increase in $\% R$ may be attributed to the greater number of available sites for dye-binding and the increased surface area of biosorbent at the higher dosage [20]. At the dosage above $0.6 \mathrm{~g} / 1, \% R$ did not considerably change due to aggregation of adsorbent which would reduce the number of binding sites available to dye molecules. Consequently, increasing the dosage to a certain level reduces the quantity of CV bound onto unit mass of MOPH $[18,20]$. From the above results, a MOPH dosage of $0.6 \mathrm{~g} / 1$ was selected for further studies.

\section{Effect of initial $\mathrm{pH}$}

The effect of solution $\mathrm{pH}$ on adsorption of $\mathrm{CV}$ is shown in Fig. 3c. The $\mathrm{pH}_{\mathrm{pzc}}$ of $\mathrm{MOPH}$ was also determined to elucidate the $\mathrm{pH}$ influence on CV uptake, and it was found to be 5.1 (Fig. 3d). We found that both $\% R$ and $q$ were low as $\mathrm{pH}$ was below $\mathrm{pH}_{\mathrm{pzc}}$ (Fig. 3c) because the electrostatic repulsion occurred between the positive charges on both MOPH and CV surfaces [18]. When pH of CV solution was greater than 5 , the electrostatic inter- action was promoted between the electronegative biosorbent surface and the cationic dye, resulting in the enhancement of CV adsorption on MOPH [18]. According to the results, a CV solution at $\mathrm{pH} 6$ was used in further studies.

\section{Adsorption kinetics}

The kinetic experiment was performed by using a MOPH dose of $0.6 \mathrm{~g} / 1$ for different time intervals in solutions of different initial $\mathrm{CV}$ concentrations (50, 100 and $250 \mathrm{mg} / \mathrm{l}$ ), all at $\mathrm{pH} 6$ and $25^{\circ} \mathrm{C}$. The result in Fig. 4a demonstrates that adsorption was facilitated by the numerous binding sites on the adsorbent surface during the first $10 \mathrm{~min}$ and took place quickly at all initial CV concentrations $[4,20]$, and the plateau was attained at $60 \mathrm{~min}$ assigned as equilibrium time. Fig. 4a shows that increments of initial dye concentration increased dye adsorption capacity. At greater initial amount of CV in the solution, a high driving force existed for dye transfer from the liquid phase to adsorption sites of the adsorbent [20].

The biosorption kinetics of CV on MOPH were studied using pseudo-first order [21] and pseudosecond order [22] kinetic models, which are respec- 

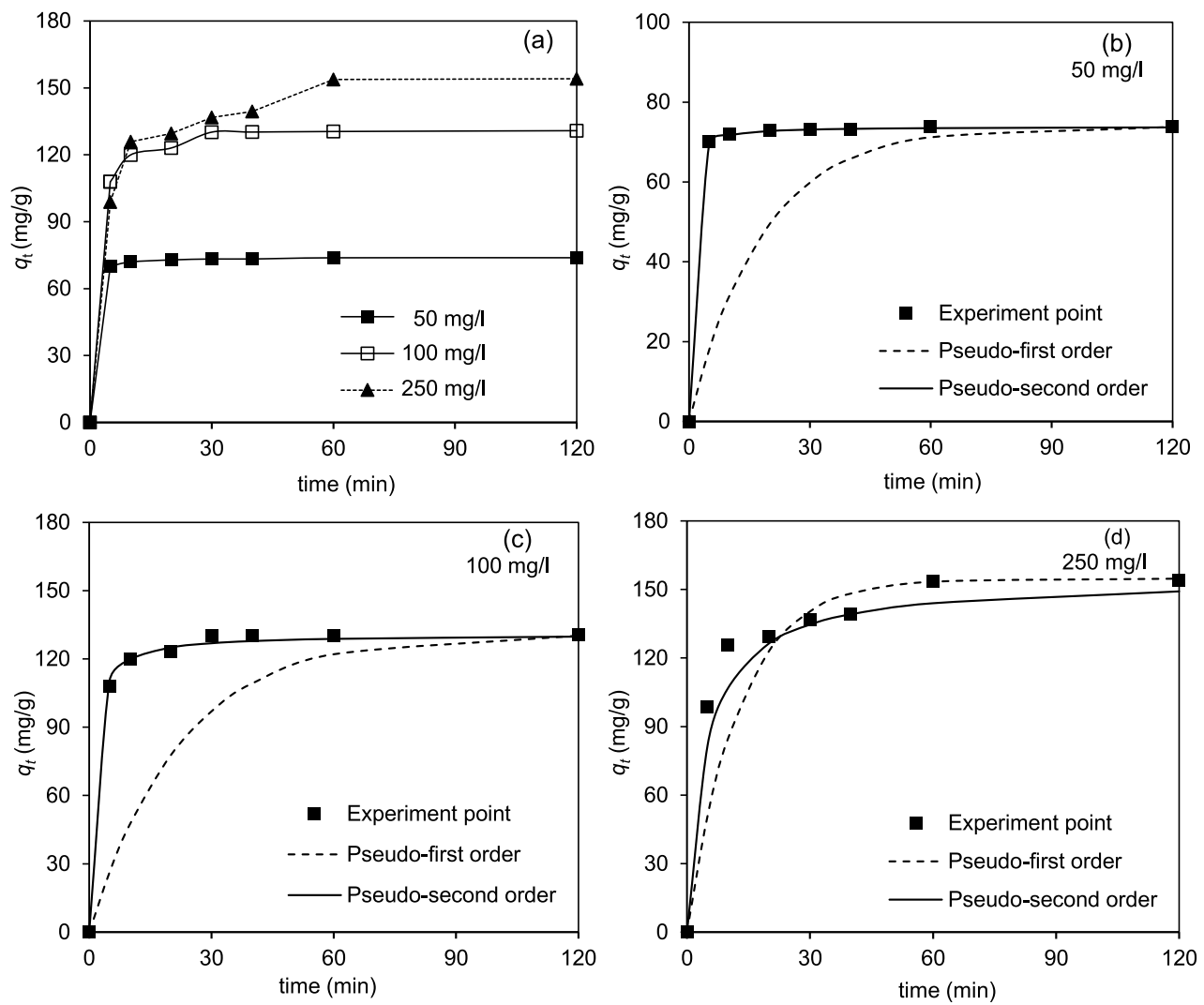

Fig. 4 Effect of contact time at different initial CV concentrations (a) and kinetic curves of CV adsorption on MOPH at $50 \mathrm{mg} / \mathrm{l}(\mathrm{b}), 100 \mathrm{mg} / \mathrm{l}$ (c) and $250 \mathrm{mg} / \mathrm{l}(\mathrm{d})$.

tively expressed in Eqs. (4) and (5):

$$
\begin{gathered}
q_{t}=q_{e}\left(1-\mathrm{e}^{-k_{1} t}\right) \\
q_{t}=\frac{k_{2} q_{e}^{2} t}{1+q_{e} k_{2} t}
\end{gathered}
$$

in which the mass of $\mathrm{CV}$ adsorbed per biosorbent mass $\left(\mathrm{mg} / \mathrm{g}\right.$ ) were defined as $q_{e}$ and $q_{t}$ at equilibrium and at a given time $t$, respectively. $k_{1}$ is the pseudo-first order rate constant $\left(\mathrm{min}^{-1}\right)$ while $k_{2}$ is the rate constant for pseudo-second order (g/mg-min). The experimental kinetic curves and the model kinetic curves are shown in Fig. 4(b-d). Table 1 lists the calculated model constants with the correlation coefficient values $\left(R^{2}\right)$. These findings indicate that the data of the kinetics of adsorption of $\mathrm{CV}$ on MOPH is suitably fitted with the pseudosecond order model for all studied initial concentrations $\left(R^{2} \geqslant 0.998\right)$. These results imply that the biosorption process of $\mathrm{CV}$ onto MOPH was governed by chemisorption [4].

\section{Adsorption isotherms}

Langmuir and Freundlich isotherms $[23,24]$ were used to study the equilibrium adsorption behavior of CV on MOPH. Adsorption isotherms was studied using adsorption data acquired at a contact time of $120 \mathrm{~min}$ to ensure that adsorption equilibrium had been completely achieved. These isotherms are described by the following equations:

$$
\begin{array}{ll}
\text { (Langmuir) } & q_{e}=\frac{q_{\max } K_{L} C_{e}}{1+K_{L} C_{e}} \\
\text { (Freundlich) } & q_{e}=K_{F} C_{e}^{1 / n}
\end{array}
$$

in which $C_{e}(\mathrm{mg} / \mathrm{l})$ is the equilibrium dye concentration in liquid phase, $q_{\max }(\mathrm{mg} / \mathrm{g})$ is the maximum adsorption capacity, $K_{L}(\mathrm{l} / \mathrm{mg})$ and $K_{F}$ $\left((\mathrm{mg} / \mathrm{g}) /(\mathrm{mg} / \mathrm{l})^{1 / n}\right)$ are the constant values of Langmuir equilibrium constant and the Freundlich, respectively, and $n$ is adsorption intensity. The parameters obtained from both adsorption isotherms are listed in Table 1. Based on the results obtained from the modelled adsorption isotherms (Fig. 5a) and the $R^{2}$, in Table 1 , the finding points for ad- 

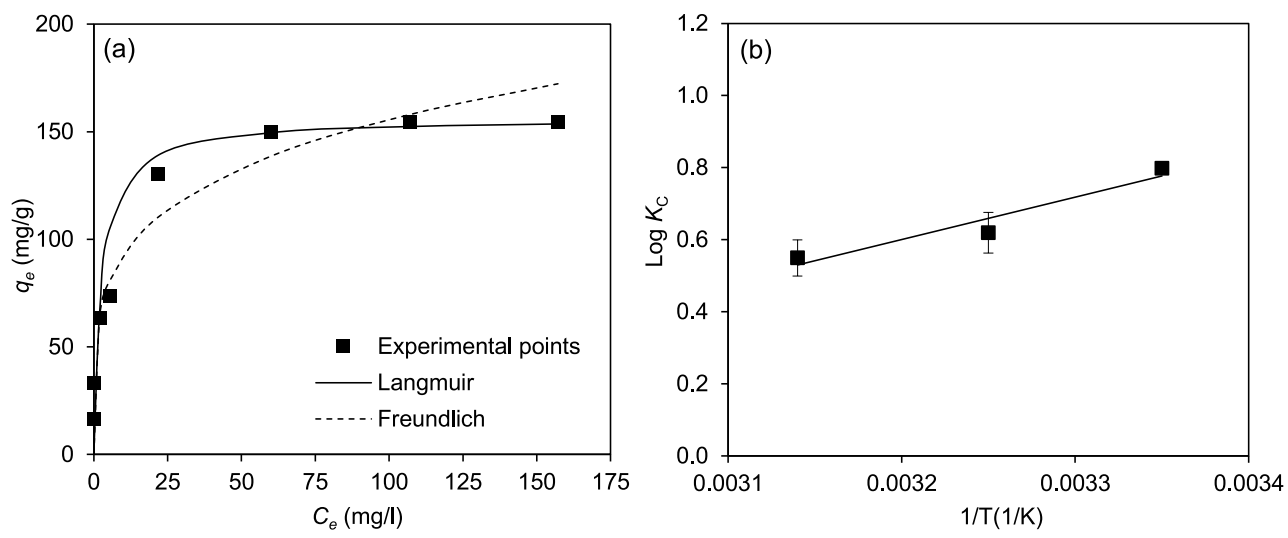

Fig. 5 Equilibrium curves (a) and Van't Hoff plot (b) for CV adsorption on MOPH.

Table 1 The pseudo-first order and pseudo-second order models and Langmuir and Freundlich isotherm parameters for CV adsorption on MOPH.

\begin{tabular}{|c|c|c|c|c|c|c|c|}
\hline \multicolumn{2}{|c|}{ Kinetic model } & \multicolumn{3}{|c|}{ Pseudo-first order } & \multicolumn{3}{|c|}{ Pseudo-second order } \\
\hline $\begin{array}{l}C_{o} \\
(\mathrm{mg} / \mathrm{l})\end{array}$ & $\begin{array}{c}q_{e, \exp } \\
(\mathrm{mg} / \mathrm{g})\end{array}$ & $\begin{array}{c}q_{e} \\
(\mathrm{mg} / \mathrm{g})\end{array}$ & $\begin{array}{c}k_{1} \\
\left(\min ^{-1}\right)\end{array}$ & $R^{2}$ & $\begin{array}{c}q_{e} \\
(\mathrm{mg} / \mathrm{g})\end{array}$ & $\begin{array}{c}k_{2} \\
(\mathrm{~g} / \mathrm{mg} \cdot \min )\end{array}$ & $R^{2}$ \\
\hline 50 & 73.85 & 3.92 & 0.055 & 0.893 & 74.07 & 0.045 & 0.999 \\
\hline 100 & 130.80 & 10.05 & 0.045 & 0.769 & 131.58 & 0.008 & 0.999 \\
\hline 250 & 154.09 & 124.59 & 0.079 & 0.966 & 158.73 & 0.001 & 0.998 \\
\hline \multicolumn{2}{|c|}{ Isotherm model } & \multicolumn{3}{|c|}{ Langmuir } & \multicolumn{3}{|c|}{ Freundlich } \\
\hline \multirow{2}{*}{\multicolumn{2}{|c|}{ Parameter }} & $\begin{array}{c}q_{\max } \\
(\mathrm{mg} / \mathrm{g})\end{array}$ & $\begin{array}{c}K_{L} \\
(1 / \mathrm{mg})\end{array}$ & $R^{2}$ & $\begin{array}{c}K_{F} \\
(\mathrm{mg} / \mathrm{g}) /(\mathrm{mg} / \mathrm{l})^{1 / n}\end{array}$ & $n$ & $R^{2}$ \\
\hline & & 156.250 & 0.372 & 0.999 & 55.043 & 4.431 & 0.931 \\
\hline
\end{tabular}

sorption of $\mathrm{CV}$ on $\mathrm{MOPH}$ at equilibrium state fit best with the Langmuir model. This correlation suggests monolayer adsorption behavior. The $q_{\max }$ from the Langmuir model was $156.25 \mathrm{mg} / \mathrm{g}$, which is larger than the capacity achieved by some biosorbents with and without chemical treatment (Fig. 6). Moreover, the biosorbent in the present study showed a high adsorption capacity by comparison with effective carbon-based adsorbents that required more materials, energy or processing during fabrication (Fig. 6). The adsorption capacities and equilibrium adsorption times $\left(t_{\mathrm{eq}}\right)$ presented in Fig. 6 imply that $\mathrm{MOPH}$ is an alternative, efficient and environmentally friendly biosorbent for adsorption of $\mathrm{CV}$ in water.

\section{Adsorption thermodynamics}

The adsorption of CV on MOPH was studied at 298, 308 and $318 \mathrm{~K}$. The Gibb's free energy $\left(\Delta G^{\circ}\right)$ can be calculated using Eqs. (8) and (9):

$$
\begin{gathered}
K_{C}=\frac{C_{\mathrm{ae}}}{C_{e}} \\
\Delta G^{\circ}=-R T \ln K_{C} \\
\ln K_{C}=\frac{\Delta S^{\circ}}{R}-\frac{\Delta H^{\circ}}{R T}
\end{gathered}
$$

where $K_{C}$ is the constant value at equilibrium. $T$ $(\mathrm{K})$ and $R(\mathrm{~J} / \mathrm{K} \cdot \mathrm{mol})$ are temperature and the gas constant, respectively. The enthalpy $\left(\Delta H^{\circ}\right)$ and entropy $\left(\Delta S^{\circ}\right)$ can be evaluated using Eq. (10). The slope and intercept from the plot in Fig. 5b yielded the $\Delta H^{\circ}$ and $\Delta S^{\circ}$ values, respectively.

The values of $\Delta G^{\circ}$ were $-4.557(298 \mathrm{~K})$, $-3.653(308 \mathrm{~K})$ and $-3.346 \mathrm{~kJ} / \mathrm{mol}(318 \mathrm{~K})$, implying the spontaneous process [19]. The increment of $\Delta G^{\circ}$ with temperature implies that sorption proceeded more easily at lower temperatures [6]. The $\Delta H^{\circ}$ value was negative $(-22.483 \mathrm{~kJ} / \mathrm{mol})$, suggesting that the sorption of $\mathrm{CV}$ on $\mathrm{MOPH}$ was 


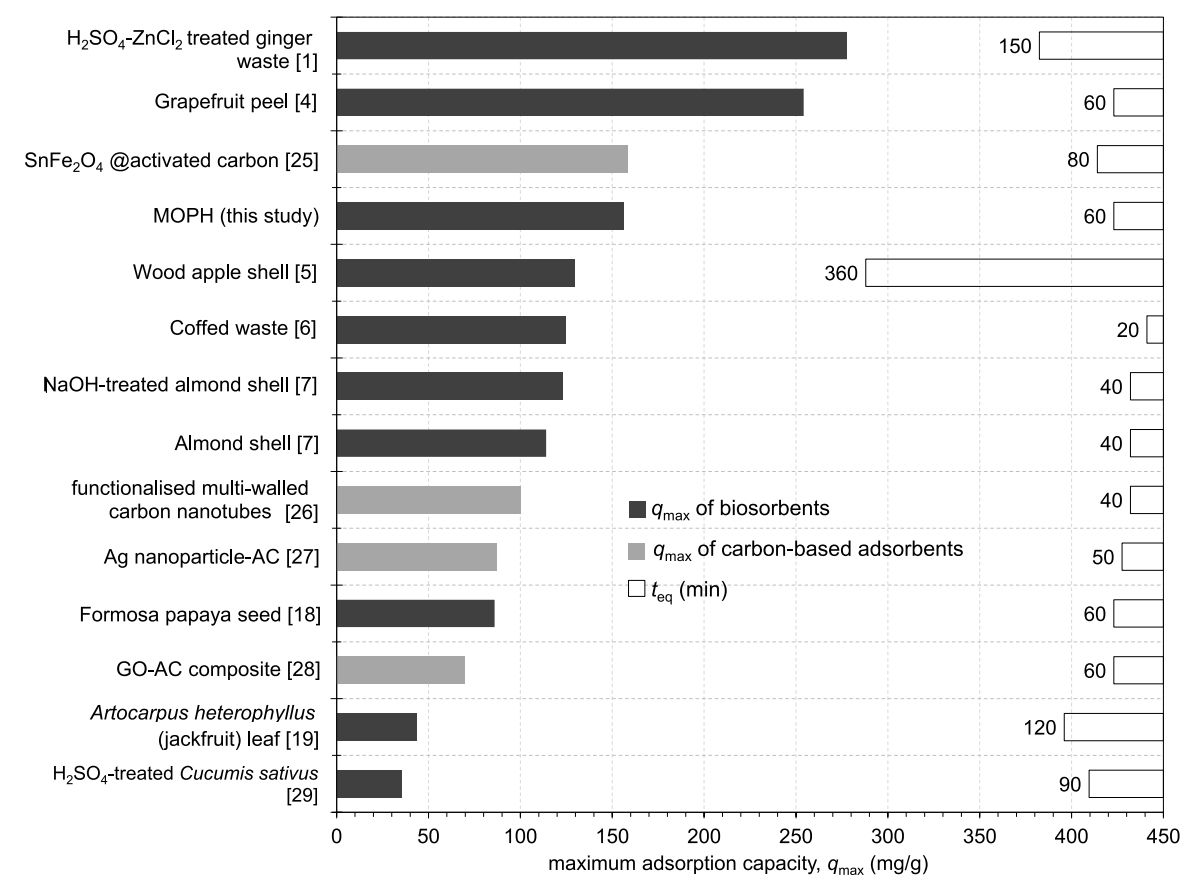

Fig. 6 Maximum adsorption capacity of various adsorbents from Langmuir isotherm model for CV removal and their equilibrium adsorption time.
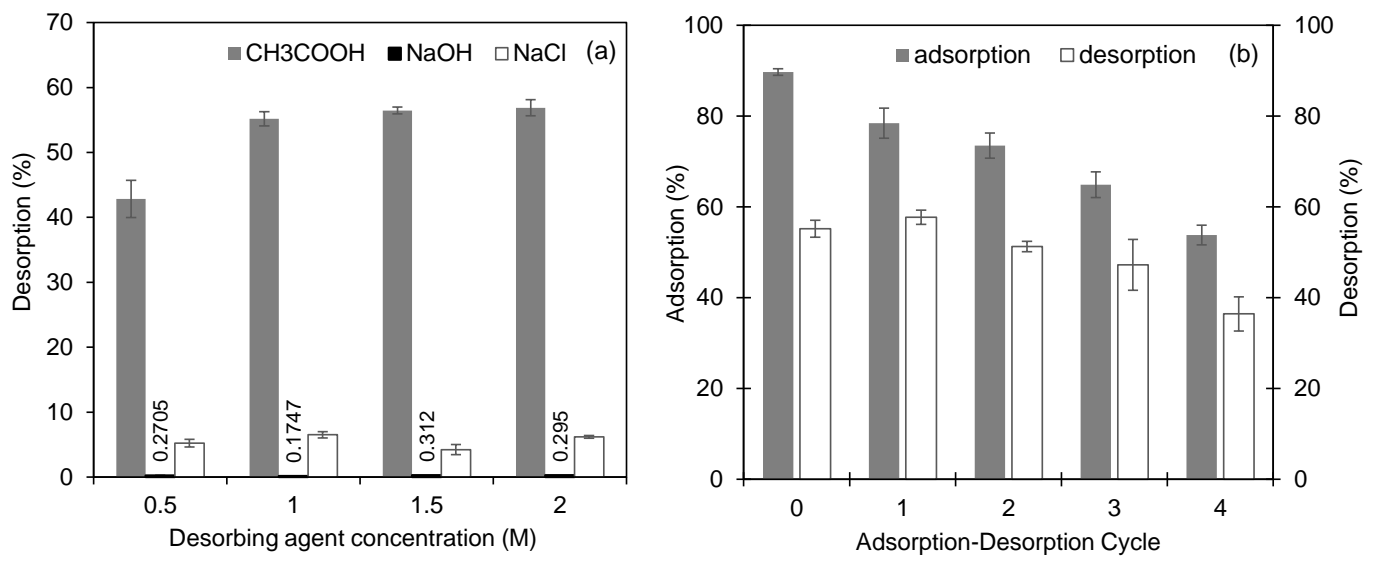

Fig. 7 Effect of desorbing agents and their concentrations on the desorption of CV from MOPH (a) and adsorptiondesorption cycle of MOPH by $1 \mathrm{M}$ acetic acid solution (b).

exothermic, and a reduction in randomness of $\mathrm{CV}$ at interface between solid and liquid was implied by the negative $\Delta S^{\circ}(-60.446 \mathrm{~J} / \mathrm{mol} \cdot \mathrm{K})[30]$. Similar findings were reported for adsorption of CV by coffee waste [6] and Artocarpus heterophyllus (jackfruit) leaf powder [19].

\section{Desorption studies}

The recovery of adsorbed $\mathrm{CV}$ and the regeneration of the MOPH biosorbent were investigated in a bath desorption study using aqueous solutions of $\mathrm{CH}_{3} \mathrm{COOH}, \mathrm{NaOH}$ and $\mathrm{NaCl}$ at $0.5,1.0,1.5$ and 2.0 $\mathrm{mol} / 1$ at $25^{\circ} \mathrm{C}$. The aqueous solution of $\mathrm{CH}_{3} \mathrm{COOH}$ exhibited the highest desorption capacity at all concentrations (Fig. 7a). Desorption capacity increased from $42.86 \pm 2.87 \%$ for $0.5 \mathrm{~mol} / 1 \mathrm{CH}_{3} \mathrm{COOH}$ to $55.17 \pm 1.08 \%$ for $1 \mathrm{~mol} / 1 \mathrm{CH}_{3} \mathrm{COOH}$. Thereafter, desorption capacity did not change significantly. The desorption capacity of $\mathrm{CH}_{3} \mathrm{COOH}$ solution was attributed to the ability of protons in the acidic 


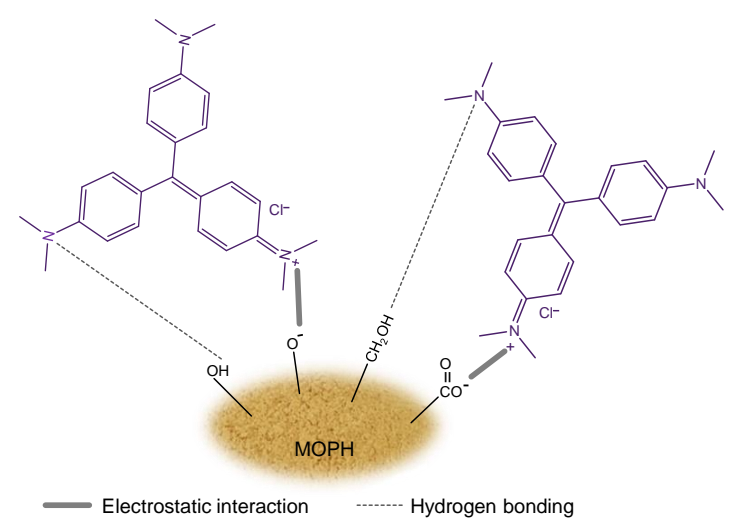

Fig. 8 Proposed adsorption mechanism of CV on MOPH.

solution to replace the cations adsorbed on the adsorbent [31]. The inverse effect was obtained with the $\mathrm{NaOH}$ medium. These results suggest the formation of electrostatic attraction between the biosorbent and the cationic dye [18]. Based on the efficient desorption of $\mathrm{CV}$ from the biosorbent and low cost, a $\mathrm{CH}_{3} \mathrm{COOH}$ solution of $1 \mathrm{M}$ was selected as the desorption agent for further study.

Although CV was not completely desorbed from $\mathrm{MOPH}$, the re-adsorption of MOPH after desorption by $1 \mathrm{M} \mathrm{CH}_{3} \mathrm{COOH}$ solution was investigated to evaluate the reusability of the biosorbent. Fig. $7 \mathrm{~b}$ demonstrates that the adsorption of CV decreased from $89.72 \pm 0.70 \%$ in the initial cycle to $78.45 \pm 3.31 \%$ in the first recycling. In the fourth cycle, the percentage of dye adsorbed decreased to $53.81 \pm 2.19 \%$. Many reasons could describe a reduction of adsorption capacity: occupation by $\mathrm{CV}$ molecules of the adsorption sites on the MOPH, degradation of cellulosic biosorbent in acidic media and generation of positive charges on MOPH surface by the acidic desorbing agent [32].

\section{Adsorption mechanism}

The adsorption revealed by FTIR in Fig. 2 shows that the peak at $1583 \mathrm{~cm}^{-1}$ derived from $\mathrm{C}-\mathrm{N}$ groups of the $\mathrm{CV}$ molecule was observed in $\mathrm{CV}$ loaded MOPH. The peaks present in pretreated MOPH at 3415 and $1633 \mathrm{~cm}^{-1}$ moved to 3330 and $1647 \mathrm{~cm}^{-1}$, respectively, in the CV-loaded adsorbent. Moreover, the peak at $1157 \mathrm{~cm}^{-1}$ shifted to $1166 \mathrm{~cm}^{-1}$. These results indicated the presence of intermolecular between MOPH and CV. Moreover, the desorption results proved that $\mathrm{CV}$ was strongly adsorbed on MOPH. It can be inferred that CV adsorbed on MOPH not only by electrostatic interac- tion of the positive and negative charges between $\mathrm{CV}$ and MOPH but also by hydrogen bonding between nitrogen atoms in CV and hydrogen atoms in hydroxyl or carboxylic groups of MOPH $[1,18]$. The proposed adsorption mechanism of $\mathrm{CV}$ on $\mathrm{MOPH}$ was depicted in Fig. 8.

\section{CONCLUSION}

A biosorbent was prepared from Moringa oleifera pod husk and investigated for adsorption of $\mathrm{CV}$ in water. SEM micrograph of the lignocellulosic biomass revealed a porous and rough surface that facilitated the interaction between $\mathrm{CV}$ and MOPH. The MOPH presented a BET surface area of $2.097 \mathrm{~m}^{2} / \mathrm{g}$ and $\mathrm{pH}_{\mathrm{pzc}}$ of 5.1. The adsorption capacity of MOPH increased as $\mathrm{pH}$ and initial CV concentration increased. The experimental data agreed well with the pseudo-second order and the Langmuir isotherm models. The thermodynamic study of $\mathrm{CV}$ adsorption on MOPH indicated a spontaneous and exothermic process. Desorption of the adsorbed $\mathrm{CV}$ and regeneration of the MOPH was possible using acetic acid solution. The results of this study indicated that the environmentally friendly and low cost MOPH biosorbent could provide an alternative means of cationic dye removal.

Acknowledgements: The authors acknowledge the budget revenue of Prince of Songkla University [Contract No. SCI610556S] for the financial support. The authors are also grateful to Faculty of Science, Prince of Songkla Univerisity for Research Assistantship for Mr. Adisak Keereerak [Contract No. 1255902014]. We also acknowledge Mr. Thomas Coyne for his kind assistance in editing the English.

\section{REFERENCES}

1. Kumar R, Ahmad R (2011) Biosorption of hazardous crystal violet dye from aqueous solution onto treated ginger waste (TGW). Desalination 265, 112-118.

2. Oguntimein GB (2015) Biosorption of dye from textile wastewater effluent onto alkali treated dried sunflower seed hull and design of a batch adsorber. $J$ Environ Chem Eng 3, 2647-2661.

3. Bonilla-Petriciolet A, Mendoza-Castillo DI, ReynelÁvila HE (2017) Adsorption Processes for Water Treatment and Purification, Springer, Cham.

4. Saeed A, Sharif M, Iqbal M (2010) Application potential of grapefruit peel as dye sorbent: kinetics, equilibrium and mechanism of crystal violet adsorption. J Hazard Mater 179, 564-572.

5. Jain S, Jayaram RV (2010) Removal of basic dyes from aqueous solution by low-cost adsorbent: wood apple shell (Feronia acidissima). Desalination 250, 921-927. 
6. Lafi R, ben Fradj A, Hafiane A, Hameed BH (2014) Coffee waste as potential adsorbent for the removal of basic dyes from aqueous solution. Korean $J$ Chem Eng 31, 2198-2206.

7. Ishaq M, Javed F, Amad I, Ullah H, Hadi F, Sultan S (2016) Adsorption of crystal violet dye from aqueous solutions onto low-cost untreated and $\mathrm{NaOH}$ treated almond shell. Iran J Chem Chem Eng 35, 97-106.

8. Bhatti HN, Mumtaz B, Hanif MA, Nadeem R (2007) Removal of $\mathrm{Zn}$ (II) ions from aqueous solution using Moringa oleifera Lam. (horseradish tree) biomass. Process Biochem 42, 547-553.

9. Reddy DHK, Ramana DKV, Seshaiah K, Reddy AVR (2011) Biosorption of Ni(II) from aqueous phase by Moringa oleifera bark, a low cost biosorbent. Desalination 268, 150-157.

10. Gopalakrishnan L, Doriya K, Kumar DS (2016) A review on nutritive importance and its medicinal application. Food Sci Hum Wellness 5, 49-56.

11. Reck IM, Paixão RM, Bergamasco R, Vieira MF, Vieira AMS (2018) Removal of tartrazine from aqueous solutions using adsorbents based on activated carbon and Moringa oleifera seeds. J Clean Prod 171, 85-97.

12. Tie J, Li P, Xu Z, Zhou Y, Li C, Zhang X (2015) Removal of Congo red from aqueous solution using Moringa oleifera seed cake as natural coagulant. Desalin Water Treat 54, 2817-2824.

13. Lopez-Ramon MV, Stoeckli F, Moreno-Castilla C, Carrasco-Marin F (1999) On the characterization of acidic and basic surface sites on carbons by various techniques. Carbon 37, 1215-1221.

14. Khalil HPSA, Ismail H, Rozman HD, Ahmad MN (2001) Effect of acetylation on interfacial shear strength between plant fibres and various matrices. Eur Polym J 37, 1037-1045.

15. Karimi S, Tahir PM, Karimi A, Dufresne A, Abdulkhani A (2014) Kenaf bast cellulosic fibers hierarchy: A comprehensive approach from micro to nano. Carbohydr Polym 101, 878-885.

16. Wang B, Sain M, Oksman K (2007) Study of structural morphology of hemp fiber from the micro to the nanoscale. Appl Compos Mater 14, 89-103.

17. Kaushik A, Singh M (2011) Isolation and characterization of cellulose nanofibrils from wheat straw using steam explosion coupled with high shear homogenization. Carbohydr Res 346, 76-85.

18. Pavan FA, Camacho ES, Lima EC, Dotto GL, Branco VTA, Dias SLP (2014) Formosa papaya seed powder (FPSP): Preparation, characterization and application as an alternative adsorbent for the removal of crystal violet from aqueous phase. $J$ Environ Chem Eng 2, 230-238.

19. Saha PD, Chakraborty S, Chowdhury S (2012) Batch and continuous (fixed-bed column) biosorption of crystal violet by Artocarpus heterophyllus (jackfruit) leaf powder. Colloids Surfaces B Biointerfaces 92, 262-270.

20. Saha P, Chowdhury S, Gupta S, Kumar I (2010) Insight into adsorption equilibrium, kinetics and thermodynamics of malachite green onto clayey soil of Indian origin. Chem Eng $J$ 165, 874-882.

21. Lagergren S (1898) Zur theorie der sogenannten adsorption gelöster stoffe. K Sven Vetenskapsakad Handl 24, 1-39.

22. Ho YS, Mckay G (1999) Pseudo-second order model for sorption processes. Process Biochem 34, 451-465.

23. Langmuir I (1918) The adsorption of gases on plane surfaces of glass, mica, and platinum. J Am Chem Soc 40, 1361-1403.

24. Freundlich H, Helle WJ (1939) Adsorption in solution. J Am Chem Soc 61, 2228-2230.

25. Rai P, Gautam RK, Banerjee S, Rawat V, Chattopadhyaya MC (2015) Synthesis and characterization of a novel $\mathrm{SnFe}_{2} \mathrm{O}_{4}$ @activated carbon magnetic nanocomposite and its effectiveness in the removal of crystal violet from aqueous solution. $J$ Environ Chem Eng 3, 2281-2291.

26. Sabna V, Thampi SG, Chandrakaran S (2016) Adsorption of crystal violet onto functionalised multi-walled carbon nanotubes: equilibrium and kinetic studie. Ecotoxicol Environ Saf 134, 390-397.

27. AbdEl-Salam AH, Ewais HA, Basaleh AS (2017) Silver nanoparticles immobilised on the activated carbon as efficient adsorbent for removal of crystal violet dye from aqueous solutions. A kinetic study. $J$ Mol Liq 248, 833-841.

28. Abd-Elhamid AI, Kamoun EA, El-Shanshory AA, Soliman HMA, Aly HF (2019) Evaluation of graphene oxide-activated carbon as effective composite adsorbent toward the removal of cationic dyes: composite preparation, characterization and adsorption parameters. J Mol Liq 279, 530-539.

29. Smitha T, Santhi T, Prasad AL, Manonmani S (2017) Cucumis sativus used as adsorbent for the removal of dyes from aqueous solution. Arab $J$ Chem 10, S244-S251.

30. Chigbundu EC, Adebowale KO (2017) Equilibrium and fractal-like kinetic studies of the sorption of acid and basic dyes onto watermelon shell (Citrullus vulgaris). Cellulose 24, 4701-4714.

31. Cechinel MAP, Ulson De Souza SMAG, Ulson De Souza AA (2014) Study of lead (II) adsorption onto activated carbon originating from cow bone. J Clean Prod 65, 342-349.

32. Daneshvar E, Vazirzadeh A, Niazi A, Kousha M, Naushad M, Bhatnagar A (2017) Desorption of methylene blue dye from brown macroalgaâĂŕ: effects of operating parameters, isotherm study and kinetic modeling. J Clean Prod 152, 443-453. 